\title{
A Randomized Community-based Intervention Trial Comparing Faith Community Nurse Referrals to Telephone-Assisted Physician Appointments for Health Fair Participants with Elevated Blood Pressure
}

\author{
Arshiya A. Baig, MD, MPH', Carol M. Mangione, MD, $\mathrm{MSPH}^{2}$, \\ Alice L. Sorrell-Thompson, MBA, PHN, $R N^{3}$, and Jeanne M. Miranda, $P h D^{4}$ \\ 'Department of Medicine, Section of General Internal Medicine, University of Chicago, Chicago, IL, USA; ${ }^{2}$ Department of Medicine, Division of \\ General Internal Medicine and Health Services Research, University of California, Los Angeles, CA, USA; ${ }^{3}$ Haven Health, Los Angeles, CA, USA; \\ ${ }^{4}$ Department of Psychiatry and Biobehavioral Sciences, University of California, Los Angeles, CA, USA.
}

OBJECTIVE: To measure the effect of faith community nurse referrals versus telephone-assisted physician appointments on blood pressure control among persons with elevated blood pressure at health fairs.

METHODS: Randomized community-based intervention trial conducted from October 2006 to October 2007 of 100 adults who had an average blood pressure reading equal to or above a systolic of $140 \mathrm{~mm} \mathrm{Hg}$ or a diastolic of $90 \mathrm{~mm} \mathrm{Hg}$ obtained at a faith community nurse-led church health event. Participants were randomized to either referral to a faith community nurse or to a telephone-assisted physician appointment. The average enrollment systolic blood pressure (SBP) was $149 \pm 14 \mathrm{~mm} \mathrm{Hg}$, diastolic blood pressure (DBP) was $87 \pm 11 \mathrm{~mm} \mathrm{Hg}, 57 \%$ were uninsured and $25 \%$ were undiagnosed at the time of enrollment.

RESULTS: The follow-up rate was $85 \%$ at 4 months. Patients in the faith community nurse referral arm had a $7 \pm 15 \mathrm{~mm} \mathrm{Hg}$ drop in SBP versus a $14 \pm 15 \mathrm{~mm} \mathrm{Hg}$ drop in the telephone-assisted physician appointment $\operatorname{arm}(p=0.04)$. Twenty-seven percent of the patients in the faith community nurse referral arm had medication intensification compared to $32 \%$ in the telephoneassisted physician appointment arm $(\mathrm{p}=0.98)$.

CONCLUSIONS: Church health fairs conducted in lowincome, multiethnic communities can identify many people with elevated blood pressure. Facilitating physician appointments for people with elevated blood pressure identified at health fairs confers a greater decrease in SBP than referral to a faith community nurse at four months.

KEY WORDS: community-based intervention; hypertension; health fairs; disparities.

$\mathrm{J}$ Gen Intern Med 25(7):701-9

DOI: $10.1007 / \mathrm{s} 11606-010-1326-9$

(C) The Author(s) 2010. This article is published with open access at Springerlink.com

Electronic supplementary material The online version of this article (doi:10.1007/s11606-010-1326-9) contains supplementary material, which is available to authorized users.

Received June 12, 2009

Revised December 21, 2009

Accepted March 4, 2010

Published online March 27, 2010

\section{BACKGROUND}

Racial disparities exist in the prevalence, diagnosis, treatment and control of hypertension. ${ }^{1-12}$ Poorly controlled hypertension can increase the risk of stroke, heart disease, kidney disease and overall mortality. ${ }^{13-16}$ In an effort to decrease disparities in hypertension, organizations have used health fairs in underserved communities to promote awareness, offer screenings, and disseminate health education.

Faith community nurses work to improve the health of their communities and may help eliminate disparities in health by counseling patients and facilitating access to care. ${ }^{17-32}$ Their services may be particularly important in poor communities where congregants lack a usual source of care and experience many delays in accessing care. ${ }^{16}$

In this study, we compare referrals to faith community nurses to telephone assistance with making physician appointments. Telephone-based interventions have been effective in improving care and outcomes in disadvantaged persons with chronic conditions. ${ }^{33-35}$ We chose to measure change in systolic blood pressure to assess if these interventions would have an effect on a major clinical outcome. We also measured more proximal outcomes, such as medication adherence, medication intensification, and self-care, to measure processes of care. To our knowledge this is the first randomized trial that has evaluated a follow-up intervention for health fair participants identified as having uncontrolled blood pressure. Using a community-based participatory research approach, we examined the effect of referrals to faith community nurses versus telephone-assisted physician appointments among individuals identified as having elevated blood pressure on the following: 1) systolic blood pressure control; 2) antihypertensive medication intensification; 3) knowledge about hypertension; and 4) participation in selfcare. Testing these two interventions allows us to assess if a faith community nurse forming a relationship with participants, educating them on hypertension, and linking them to care is more beneficial than linking participants directly to medical care.

\section{METHODS}

We established a collaborative partnership with an established faith community nurse program in Los Angeles through 
QueensCare, a nonprofit organization that manages a number of safety net clinics and has several community outreach programs. QueensCare hires registered nurses to serve as faith community nurses at partnered churches. These nurses hold office hours at the churches and deliver services to the community. The nurses were not selected or trained for this study since they were already a part of a program operating in the community.

The academic team worked with the faith community nurses in identifying the research question, determining the study measures, designing the study, recruiting participants, and analyzing the results. We conducted a randomized intervention trial and enrolled participants from faith community nurse sponsored health fairs at churches. Participants were recruited from October 2006 to June 2007 and followed-up from February 2007 to October 2007. Participants who were eligible for the study provided written informed consent. The UCLA institutional review board approved all study procedures, and this trial was registered at clinicaltrials.gov identifier NCT00535444.

\section{Participants}

From October 2006 to June 2007, we measured blood pressures of 886 health fair participants 18 years or older at 26 health fairs at 11 churches in Los Angeles County. The nurse-led church health fairs were diverse. They attracted a variety of heath fair participants and offered a range of health services and health information.

Figure 1 depicts the screening and enrollment process for the study. One hundred eighty seven participants had an average of the last two of three blood pressure readings equal to or over $140 \mathrm{~mm} \mathrm{Hg}$ systolic or $90 \mathrm{~mm} \mathrm{Hg}$ diastolic according to the Multiple Risk Factor Intervention Trial protocol. ${ }^{36}$ Of these participants, 37 met exclusion criteria due to inability to speak English or Spanish, being pregnant, unable to give informed consent, unable to attend the follow-up appointment, or having visited a faith community nurse within the last six months. Fifty eligible participants were not interested due to lack of interest, lack of time, or wanting to see their own physician. Of the 100 enrollees, 50 participants were randomly assigned to each intervention arm. The non-enrollees and enrollees did not differ in age, gender, race/ethnicity or systolic or diastolic blood pressure.

\section{Interventions}

We worked with our community partners to devise a comparison intervention that would best allow us to measure faith community nurse referrals without having a usual care arm, which in this uninsured and underinsured population would translate to no care. We chose to compare faith community nurse referrals to a minimal primary care physician referral intervention. Upon enrollment, participants were randomly assigned to the following: referral to a faith community nurse or telephone assistance with making a physician appointment. The participants, the faith community nurses, and the physicians were not blinded to the randomization arm. Figure 2 describes the flow of participants through the faith community intervention arm. Figure 3 in the online appendix describes the flow of participants through telephone-assisted physician appointment arm.

Faith Community Nurse Intervention. Participants randomized to the nurse referral arm were introduced to the nurse at the health fair, were given a letter with her contact information, and were encouraged to see her at least once during the next two weeks. All the faith community nurses were registered nurses and were not licensed to prescribe or dispense medications to participants. The nurses followed their standard protocol for referring a participant with hypertension (See Fig. 4 in the online appendix). The nurses could incorporate spiritual aspects into their patient encounters, but we did not obligate them to use faith in caring for their patients.

Telephone-Assisted Physician Appointment Intervention. Participants randomized to the telephone-assisted physician appointment arm received telephone assistance in making an appointment with their primary care physician (PCP). If the participant did not have a PCP, the research assistant assigned the participant to a PCP in a free-clinic in the community. Since the recruitment occurred on Sundays, the research assistants made appointments during the week and relayed the time and date of the appointment to the study participant through a phone conversation, a mailed letter, or a phone message. The participant could also elect to keep an appointment they already had with their physician or make their own appointment.

\section{Data Collection and Outcome Measures}

Trained research assistants who were blinded to the randomization arm enrolled participants into the study at the health fairs. After enrollment and collection of baseline measures, the research assistants gave participants a sealed enveloped that revealed their randomization arm. Participants received monthly flyers thanking them for their participation and reminding them of their follow-up appointment. Participants also received a reminder phone call one week and three days prior to the follow-up appointment. Follow-up measurements were obtained 4 months post-randomization by a new set of trained research assistants who were blinded to the study objectives and the participant's randomization assignment.

Demographic Characteristics. We measured participant age, gender, and race/ethnicity, employment status, income, educational attainment, and marital status. Participants reported their type of health insurance, smoking status, and primary language spoken. Patients also reported having a usual source of care, having seen a physician in the past month, having a family history of hypertension, and having a diagnosis of hypertension, diabetes, or heart disease. We used patient selfreport to determine a known diagnosis of hypertension. ${ }^{1-4}$

\section{Service Use.}

Provider Visits. Physician visits' attendance was measured by participant self-report. We verified attendance at nurse office hours through patient self-report and nurse record review. 


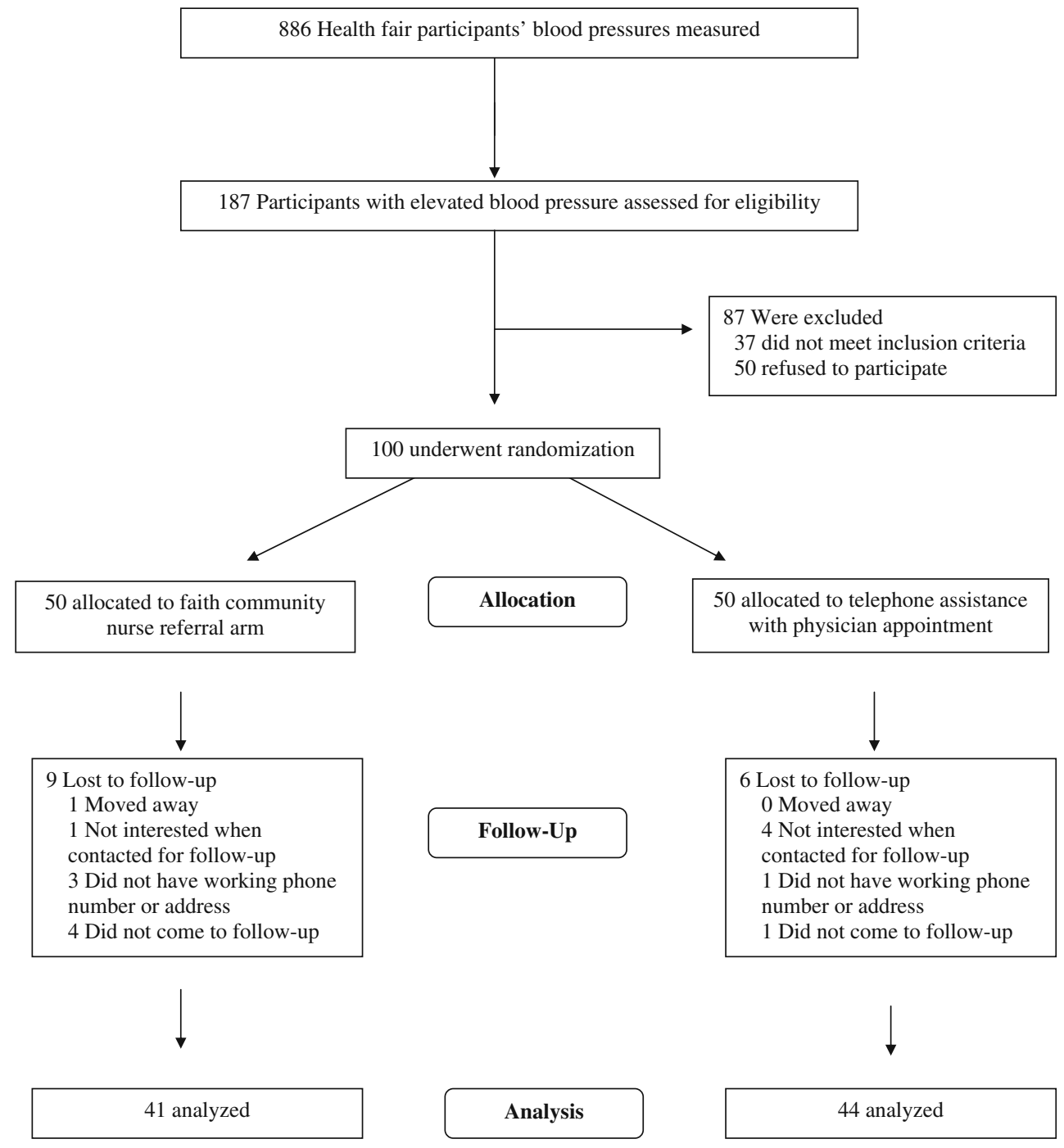

Figure 1. Recruitment and enrollment flow diagram.

Counseling. We asked patients in the follow-up interview about counseling services provided by their physician and the faith community nurse.

\section{Hypertension Outcomes.}

Blood Pressure Change. The primary outcome was change in systolic blood pressure from recruitment measured at the 4-month follow-up appointment.

Medication Intensification and Adherence. Medication intensification was defined as having an increase in the number of blood pressure medications or an increase in dosage of a given antihypertensive medication from recruitment to the 4-month follow-up appointment. Medication adherence was asked with the following question: "On how many of the past 7 days did you take your recommended blood pressure medication?"37 Participants could report zero to 7 days.
Hypertension Knowledge. We could not identify a short, reliable, and valid measure of hypertension knowledge, so we adapted six validated diabetes-specific knowledge questions from the Michigan Diabetes Research and Teaching Center (MDRTC) public use web site. ${ }^{37}$ We used the format of the MDRTC knowledge scale but changed the content to reflect hypertensive-specific content. The score on the knowledge test ranged from $0 \%$ to $100 \%$ reflecting the percentage of questions correct on the test per the instrument scoring guidelines. The Cronbach alpha for this scale was 0.65 .

Hypertension Self-care. Those who had a known diagnosis of hypertension at recruitment also completed questions regarding hypertension self-care behaviors. We adapted validated self-care questions from the MDRTC diabetes self care survey and changed the content to reflect hypertensive self-care. ${ }^{38}$ Participants indicated whether or not they had undertaken seven self-care behaviors (score: $1=$ yes, $0=$ no). 


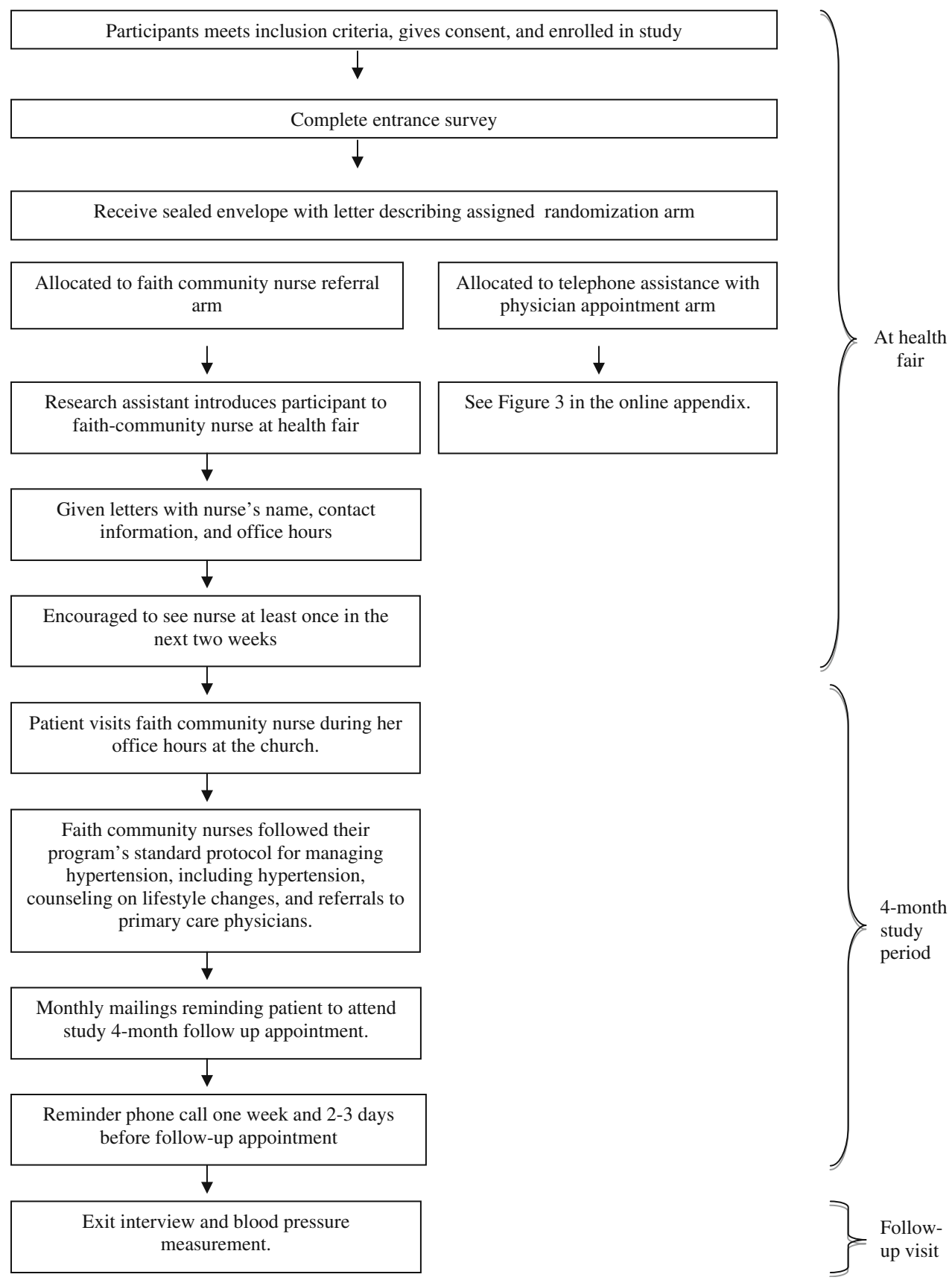

Figure 2. Flow of patients assigned to faith community nurse intervention.

The seven responses were then averaged for a composite selfcare score that ranged from zero to one per the instrument scoring guidelines.

\section{Data Analyses}

We assessed whether there was variation in demographic and/ or health characteristics by whether a person consented to participate or not. We also used univariate tests for two independent samples to compare the distribution of demo- graphic and clinical characteristics by study arm. Counseling outcomes were analyzed as dichotomous variables using chisquared tests. Difference in systolic blood pressure from enrollment to follow-up was tested as a change score, comparing means using unadjusted t-tests between the two interventions. We did conduct analyses accounting for clustering by faith community nurse and found no difference in our primary outcome. Medication intensification was analyzed as a dichotomous variable (having had medication intensification or not) for each participant and tested using chi-squared tests between the two interventions groups. Medication adherence was analyzed as a change score, comparing means using unadjusted t-tests between the two study arms. We analyzed 
knowledge score and self-care score as differences from enrollment to follow-up as change scores using unadjusted t-tests to test means.

All participants with available follow-up blood pressure readings and interview data were analyzed within the group they were assigned. A target sample size of fifty participants in each arm assumed a $12.5 \mathrm{~mm} \mathrm{Hg}$ difference in drop in systolic blood pressure between the two intervention arms with a power of 0.80 . We conducted our analyses using STATA 10.0 (StataCorp, College Station, Texas) and SAS, version 9.1 (SAS Institute Inc, Cary, North Carolina), and $\mathrm{p}<0.05$ was considered significant.

\section{RESULTS}

The sample was predominantly over 45 years of age and of ethnic minority backgrounds (Table 1). About one-third of the participants did not hold a high school degree. The majority of the participants reported an annual income less than $\$ 30,000$. About half of the participants had health insurance and the majority reported a usual source of care, though only about one-third had seen a physician in the past 4 weeks. Most had a family history of hypertension and a known diagnosis of hypertension, though less than half were on antihypertensive medications. About one-fifth also reported a diagnosis of diabetes or heart disease. The majority of the participants stated they were in poor or fair health.

Eighty-five of the participants attended the 4-month follow-up appointment at the church where they were recruited. One participant had a follow-up interview but did not have blood pressure measured. The participants who came to the follow-up appointments did not differ from the ones who were loss to followup in terms of pre-intervention blood pressure readings, gender, race/ethnicity, educational attainment, income, or insurance status. Attrition did not differ across treatment arms.

\section{Service Use}

Physician Visits. The study team made appointments for 20 of the 50 participants in the physician referral arm. Twenty-five participants in the physician referral arm kept an appointment they had and five made their own appointment. During the study period, $68 \%$ of the participants in the nurse referral arm visited a physician or spoke to one on the phone versus $80 \%$ in the telephone-assisted physician appointment arm $(\mathrm{p}=0.24)$. Participants in the telephone-assisted physician appointment arm saw a physician within $34 \pm 30$ days from being recruited to the study. In the telephone-assisted physician appointment arm, participants had the same likelihood of visiting a physician or speaking to one on the phone irrespective of

Table 1. Descriptive Data for Study Participants $(\mathrm{N}=100)$

\begin{tabular}{|c|c|c|}
\hline & \multirow{2}{*}{$\begin{array}{l}\begin{array}{l}\text { Faith community nurse referral arm } \\
\mathrm{N}=50\end{array} \\
\text { Mean (SD) or } \mathrm{N}(\%)\end{array}$} & \multirow{2}{*}{$\begin{array}{l}\text { Telephone-assisted physician appointmen } \\
\text { arm } \mathrm{N}=50 \\
\text { Mean (SD) or } \mathrm{N}(\%)\end{array}$} \\
\hline & & \\
\hline Age & $58(9)$ & $57(13)$ \\
\hline Female & $36(72)$ & $32(64)$ \\
\hline \multicolumn{3}{|l|}{ Race or ethnic group } \\
\hline Caucasian & $3(6)$ & $7(14)$ \\
\hline Hispanic & $30(60)$ & $32(64)$ \\
\hline African-American & $4(8)$ & $1(2)$ \\
\hline Asian/Pacific Islander & $12(24)$ & $10(20)$ \\
\hline Other & $1(2)$ & $0(0)$ \\
\hline Born outside of United States & $41(82)$ & $42(84)$ \\
\hline English spoken at home & $12(24)$ & $12(24)$ \\
\hline Have a high school degree or GED & $31(62)$ & $30(60)$ \\
\hline Married or living with partner & $25(50)$ & $22(44)$ \\
\hline Income greater than $\$ 30,000^{*}$ & $4(8)$ & $6(12)$ \\
\hline Employed (full time or part time) & $28(56)$ & $28(56)$ \\
\hline Currently have health insurance & $27(54)$ & $24(48)$ \\
\hline Have a usual source of care & $41(82)$ & $40(80)$ \\
\hline Have seen a physician in past 4 weeks & $17(34)$ & 19(38) \\
\hline Family history of hypertension & $31(62)$ & $29(58)$ \\
\hline Known diagnosis of hypertension & $37(74)$ & $38(76)$ \\
\hline On antihypertensive medication & $24(48)$ & $23(46)$ \\
\hline $\begin{array}{l}\text { Of past } 7 \text { days, how many days took antihypertensive } \\
\text { medications }^{\mathrm{a}}\end{array}$ & $6.6(1.39)$ & $6.4(1.88)$ \\
\hline Have never smoked & $35(70)$ & $35(70)$ \\
\hline Self-reported health status fair or poor & $29(58)$ & $25(50)$ \\
\hline Systolic blood pressure & 148(15) & $149(11)$ \\
\hline Diastolic blood pressure & $89(11)$ & $86(10)$ \\
\hline Score on knowledge test & $62(27)$ & $65(26)$ \\
\hline Self-care score & $0.8(0.25)$ & $0.7(0.29)$ \\
\hline
\end{tabular}

Due to rounding, percents may not add up to 100. Plus-minus values are means $\pm \mathrm{SD}$. Continuous variables were compared with the use of a two-sample t-test. Categorical variables were compared with the use of a chi-square test

*Four participant in the faith community nurse referral arm and 12 in the telephone-assisted physician appointment arm did not report their income

${ }^{a}$ Four participants in the faith community nurse referral arm and three participants in the telephone-assisted physician appointment arm reported being on antihypertensive medications but did not report how many of the past 7 days they took their medications 
having been given an appointment by the study team, keeping one they had or making their own $(\mathrm{p}=0.15)$.

Nurse Visits. Forty-four percent of the participants in the nurse referral arm visited or spoke with a nurse at their church versus $27 \%$ in the telephone-assisted physician appointment arm $(\mathrm{p}=0.11)$. Participants in the faith community nurse referral arm saw a nurse within $28 \pm 30$ days of recruitment.

Counseling. Patients reported medication counseling at similar rates, irrespective of study arm (Table 2). Participants in the faith community nurse referral arm were more likely to report that they had received dietary and exercise counseling. Due to the low prevalence of alcohol use and tobacco use in this patient population, patient reported physician and nurse counseling in these areas was very low.

\section{Hypertension Outcomes}

Blood Pressure Change. Participants in the faith community nurse referral arm had an average decline of $7 \pm 15 \mathrm{~mm} \mathrm{Hg}$ in systolic blood pressure versus a decline of $14 \pm 15 \mathrm{~mm} \mathrm{Hg}$ in the telephone-assisted physician appointment arm $(\mathrm{p}=0.04)$. The participants in the faith community nurse referral arm had an average drop of $3 \pm 9 \mathrm{~mm} \mathrm{Hg}$ in diastolic blood pressure compared to $6 \pm 8 \mathrm{~mm} \mathrm{Hg}$ in the telephone-assisted physician appointment $\operatorname{arm}(\mathrm{p}=0.11)$.

Medication Intensification and Adherence. Rates of medication intensification $(27 \%$ vs. $32 \%, p=0.62)$ were similar across the nurse referral and telephone-assisted physician appointment arms. Number of days in the past week that participants who were on blood pressure medications took their medications did not differ between the nurse referral $(n=22)$ or telephone-assisted physician appointment referral $(n=27)$ arm at follow-up (6.64 vs. $6.30, \mathrm{p}=0.51)$

Hypertension Knowledge. The increase in knowledge score (10\% vs. $10 \%, p=0.98)$ between the two arms was not significantly different.

Hypertension Self-care. The increase in self-care score (0.10 vs. $0.05, \mathrm{p}=0.43$ ) between the two arms was not significantly different.

Table 2. Main Outcomes According to Randomization Arm*

\begin{tabular}{|c|c|c|c|c|c|}
\hline & \multirow[b]{2}{*}{$\mathbf{N}$} & \multirow{2}{*}{$\begin{array}{l}\text { Faith community nurse referral arm } \\
\text { Mean (SD) or } N(\%)\end{array}$} & \multirow[b]{2}{*}{$\mathbf{N}$} & \multirow{2}{*}{$\begin{array}{l}\text { Telephone-assisted physician } \\
\text { appointment arm } \\
\text { Mean (SD) or } \mathrm{N}(\%)\end{array}$} & \multirow[t]{2}{*}{ P Value } \\
\hline & & & & & \\
\hline \multicolumn{6}{|l|}{ Provider seen during study period } \\
\hline Nurse only & 41 & $6(15)$ & 44 & $3(7)$ & 0.24 \\
\hline Physician only & 41 & 16(39) & 44 & 26(59) & 0.06 \\
\hline Nurse and physician & 41 & $12(30)$ & 44 & $9(20)$ & 0.35 \\
\hline Did not see nurse or physician & 41 & $7(17)$ & 44 & $6(14)$ & 0.66 \\
\hline \multicolumn{6}{|c|}{ Patient reported counseling received in provider visits ${ }^{\mathrm{a}}$} \\
\hline \multicolumn{6}{|c|}{ Dietary counseling } \\
\hline By nurse & 15 & $15(100)$ & 11 & $7(64)$ & 0.01 \\
\hline By physician & 25 & $24(96)$ & 32 & $23(72)$ & 0.02 \\
\hline \multicolumn{6}{|l|}{ Physical activity counseling } \\
\hline By nurse & 15 & $15(100)$ & 11 & $7(64)$ & 0.01 \\
\hline By physician & 26 & 25(96) & 32 & $23(72)$ & 0.02 \\
\hline \multicolumn{6}{|l|}{ Counseling on how to take medication } \\
\hline By nurse & 12 & $8(67)$ & 11 & $6(55)$ & 0.55 \\
\hline By physician & 25 & 23(92) & 29 & $24(83)$ & 0.31 \\
\hline \multicolumn{6}{|l|}{ Hypertension Outcomes } \\
\hline mm Hg drop in systolic blood pressure & 41 & $7(15)$ & 43 & $14(15)$ & 0.04 \\
\hline$\%$ received medication intensification & 41 & 23(56) & 44 & $27(61)$ & 0.62 \\
\hline$\%$ increase in knowledge score & 41 & $10(27)$ & 44 & $10(23)$ & 0.98 \\
\hline Increase in self-care score & 31 & $0.10(0.28)$ & 32 & $0.05(0.23)$ & 0.43 \\
\hline
\end{tabular}

Plus-minus values are means $\pm \mathrm{SD}$. Continuous variables were compared with the use of a two-sample t-test. Dichotomous variables were compared using chi-squared tests

*The term "nurse" refers to faith community nurse throughout the table

${ }^{a}$ The sample sizes vary in each row since not all patients who saw a nurse or physician answered the services provided questions in the follow-up questionnaire. Results are reported from the total number of responses provided. The term "nurse" refers to faith community nurse throughout the table 
a physician was sufficient for our participants to overcome these barriers. Participants in both arms of our study had at least one visit with a physician during the study period, demonstrating the success rate of the faith community nurses and the study team in referring patients to physicians. This finding is important since faith community nurses can play a central role in facilitating physician visits. ${ }^{45}$ The study team was able to facilitate these physician visits at a similar rate through telephone assistance, demonstrating the effectiveness of nonmedical personnel in assisting patients with physician appointments.

Additionally, health fairs may serve as an effective strategy in identifying persons with treatable chronic conditions. Health fairs provide an opportunity to access otherwise hard to reach populations in low-income, immigrant communities The argument for the expansion of health fairs to detected hypertension may be strengthened by the importance of early detection and treatment to prevent the consequences of uncontrolled hypertension, especially in uninsured, minority populations. ${ }^{1,2,12,46}$ Considering that churches see the value in hosting health fairs, continuing and expanding health fairs may be one way to identify persons with elevated blood pressure in these communities. ${ }^{26,27,47,48}$

\section{Counseling}

The participants in the faith community nurse referral arm were significantly more likely to report both dietary and physical activity counseling. These findings may suggest the important role of faith community nurses in counseling patients and their complementary role to physician services. Yet, we found no difference in improvement in selfcare between the study arms, perhaps pointing to the impact of low-intensity counseling on lifestyle behaviors or too short of a study period to detect significant behavioral changes. ${ }^{49-51}$

\section{Hypertension Outcomes}

Participants in the both study arms demonstrated improvements in systolic blood pressure, but those who had telephone assistance in making a physician appointment had a larger reduction in systolic blood pressure. We found no differences in medication intensification, medication adherence, or selfcare across arms to explain our findings. There may have been real differences in adherence or self-care, but the study instruments may not have been responsive to a level of change that might explain the difference in systolic blood pressure during our study period. Although both arms had similar rates of medication intensification, patients in the telephone-assisted physician appointment arm may have had more adjustments made since the average time from recruitment to their first physician appointment was likely shorter than the average time for participants who were randomized to see the nurse. Since nurses cannot prescribe medications, our finding may point to the importance prescribing antihypertensive medications in lowering systolic blood pressure.

\section{LIMITATIONS}

Our study has some limitations. Our findings may not be generalized to all populations since we recruited from health fairs, where attendees may be more activated to seek and receive healthcare. Some of the enrollees may have attended a health fair to get their blood pressures checked as part of an ongoing medical treatment program. We also could not mask the nurses to study participants due to the nature of the intervention. Self-report, particularly in relationships with power differentials, could be heavily influenced by social desirability bias; more participants could have reported attending a follow-up appointment than actually did. Also, blood pressure outcomes may reflect the counseling received instead of the referral process. Ideally, we would want to compare the content and delivery of counseling conducted by the nurses and the physicians. Unfortunately, we could not collect data from the multiple physicians who took care of the study participants, therefore we were unable to measure physician services delivered or verify if physician appointments were kept. We found that participants in the telephone-assisted physician appointment arm also visited the nurse. We did not explicitly direct the participants in that arm to avoid seeing a nurse. Since this is a small community, the participants may have heard about the nurse through other community members and visited her on their own. Also, a 4-month follow-up period may not have been enough time for behavioral changes to have an effect on outcomes. ${ }^{52}$

\section{CONCLUSION}

We found that telephone-assisted physician appointments provided a significant decline in systolic blood pressure among low-income, immigrant attendees of health fairs. Participants in the telephone-assisted physician appointment arm had a greater reduction in systolic blood pressure than in the faith community nurse referral arm. This study underscores the need for collaborative evaluations of community based interventions and that evaluations can provide evidence-based improvements in allocation of community resources and offer solutions in mitigating health disparities.

Acknowledgments: This paper was presented at the Society of General Internal Medicine Annual Meeting in April 2008. The Robert Wood Johnson Foundation Clinical Scholars Program and the Older Americans Independence Center at UCLA funded by the National Institutes of Health and National Institute on Aging (Grant no. P3OAG02874) supported this work. Dr. Baig's effort was also supported by a National Center on Minority Health and Health Disparities Loan Repayment Grant. Dr. Mangione's effort was partially supported by the UCLA Resource Centers for Minority Aging Research, 
funded by the National Institute on Aging (Grant no. P30AG021684). Dr. Jeanne Miranda's research was supported by the Resource Centers for Minority Aging Research/Center for Health Improvement of Minority Elderly (RCMAR/CHIME), funded by the National Institute on Aging (Grant no. 3P03AG021684); UCLA/Drew Project Export was funded by the National Center for Minority Health and Health Disparities (NCMHD) (Grant no. 2P2OMDO00182-06); and the UCLA-RAND Center for Research on Quality in Managed Care, funded by the National Institute of Mental Health (Grant no. P3OMHO82760 - O1). Additional contributions: We would like to thank the QueensCare Health and Faith Partnership in their support and hard work in making this project possible.

Conflict of interest: During the design phase and the implementation of this study, Alice Sorrell was the acting Director of QueensCare Health and Faith Partnership.

Open Access: This article is distributed under the terms of the Creative Commons Attribution Noncommercial License which permits any noncommercial use, distribution, and reproduction in any medium, provided the original author(s) and source are credited.

Corresponding Author: Arshiya A. Baig, MD, MPH; Department of Medicine, Section of General Internal Medicine, University of Chicago, 5841 S. Maryland Ave., MC 2007, AMB B217, Chicago, IL 60637, USA (e-mail: abaig@uchicago.edu).

\section{REFERENCES}

1. Centers for Disease Control. Racial/ethnic disparities in prevalence, treatment, and control of hypertension-United States, 1999-2002. Morbidity and Mortality Weekly Report. 2005; 54:3. Available at: http://www.cdc.gov/mmwr/preview/mmwrhtml/mm5401a3.htm. Accessed February 3, 2010.

2. Centers for Disease Control. State-specific trends in self-reported blood pressure screening and high blood pressure-United States, 1991-1999. Morb Mortal Wkly Rep. 2002;51:4

3. Hajjar I, Kotchen TA. Trends in prevalence, awareness, treatment, and control of hypertension in the United States, 1988-2000. JAMA. 2003;290(2): 199-206.

4. Sundquist $\mathbf{J}$, Winkleby $\mathbf{M}$, Pudaric $\mathbf{S}$. Cardiovascular disease risk factors among older black, Mexican-American, and white women and men: an analysis of NHANES III, 1988-1994. Third National Health and Nutrition Examination Survey. J Am Geriatr Soc. 2001;49:109-16.

5. Hyman DJ, Pavlik VN. Characteristics of patients with uncontrolled hypertension in the United States. N Engl J Med. 2001;345(7):479-486.

6. Materson BJ. Lessons on the interaction of race and antihypertensive drugs from the VA cooperative study group on antihypertensive agents. Am J Hypertens. 1995;8(12S):91S-93S.

7. Richardson AD, Piepho RW. Effect of race on hypertension and antihypertensive therapy. J Clin Pharm Ther. 2000;38:75-9.

8. He J, Klag MJ, Caballero B, Appel LJ, Charleston J, Whelton PK. Plasma insulin levels and incidence of hypertension in African Americans and Whites. Arch Intern Med. 1999;159(5):498-503.

9. Wong MD, Shapiro MF, Boscardin WJ, Ettner SL. Contribution of major diseases to disparities in mortality. N Engl J Med. 2002;347 (20): 1585-1592.

10. Hyman DJ, Pavlik VN. Uncontrolled hypertension as a risk for coronary artery disease: participant characteristics and the role of physician intervention. Curr Atheroscl Rep. 2003;5(2):131-8.

11. Chobanian AV, Bakris GL, Black HR, et al. The Seventh Report of the Joint National Committee on prevention, detection, evaluation, and treatment of high blood pressure: the JNC 7 Report. JAMA. 2003;289 (19):2560-71.

12. Smedley BD, Stith AY, Nelson AR, Institute of Medicine (U.S.) Committee on understanding and eliminating racial and ethnic disparities in health care. Unequal treatment: confronting racial and ethnic disparities in health care. Washington: National Academy Press; 2003.
13. World Health Organization. Reducing risks, promoting healthy life. Geneva: World Health Organization; 2002.

14. Crook ED, Peters M. Health disparities in chronic diseases: where the money is. Am J Med Sci. 2008;335(4):266-70.

15. Centers for Disease Control. Division for Heart Disease and Stroke Prevention Addressing the Nation's leading killers at a glance 2010 Available at: http://www.cdc.gov/nccdphp/publications/AAG/dhdsp. htm. Accessed February 3, 2010.

16. National Healthcare Disparities Report. Rockville, MD: Agency for Healthcare Research and Quality; 2007. Available at: http://www.ahrq gov/qual/nhqr07/nhqr07.pdf. Accessed February 3, 2010; 2007.

17. Benotsch EG, Stevenson LY, Sitzler CA, et al. HIV prevention in Africa: programs and populations served by non-governmental organizations. J Commun Health. 2004;29(4):319-36.

18. Weis D, Matheus R, Schank MJ. Health care delivery in faith communities: the parish nurse model. Public Health Nurs. 1997;14(6):368-72.

19. Stewart LE. Parish nursing: renewing a long tradition of caring. Gastroenterol Nurs. 2000;23(3):116-20.

20. Health Ministries Association, American Nurses Association. Faith community nursing: scope and standards of practice. Silver Spring: American Nurses Association; 2005.

21. McDonald CJ. Status of screening for skin cancer. Cancer. 1993;72(3 Suppl):1066-70.

22. Greenwald B. Health fairs: an avenue for colon health promotion in the community. Gastroenterol Nurs. 2003;26(5):191-4

23. Balasubramanyam A, Rao S, Misra R, Sekhar RV, Ballantyne CM. Prevalence of metabolic syndrome and associated risk factors in Asian Indians. J Immigr Minor Health. 2008;10(4):313-23.

24. Ellish NJ, Higginbotham EJ. Differences between screening sites in a glaucoma screening program. Ophthalmic Epidemiol. 2002;9(4):22537.

25. Dulin MK, Olive KE, Florence JA, Sliger C. The financial value of services provided by a rural community health fair. $\mathrm{J}$ Health Care Poor Underserved. 2006;17(4):821-9.

26. Boyd JL, Rothenberg R, Holcomb J. The effects of bone density testing at health fairs on awareness and treatment of osteoporosis. Arthritis Care Res. 2000;13(5):330-2.

27. Ness KK, Gurney JG, Ice GH. Screening, education, and associated behavioral responses to reduce risk for falls among people over age 65 years attending a community health fair. Phys Ther. 2003;83(7):631-7.

28. Van Zandt SE, D'Lugoff MI, Kelley L. A community-based free nursing clinic's approach to management of health problems for the uninsured: the hepatitis C example. Fam Commun Health. 2002;25(3):61-70.

29. Shiber S, D'Lugoff $\mathbf{M}$. A win-win model for an academic nursing center: community partnership faculty practice. Public Health Nurs. 2002;19 (2):81-5

30. Findley SE, Irigoyen $\mathbf{M}$, See $\mathbf{D}$, et al. Community-provider partnerships to reduce immunization disparities: field report from northern Manhattan. Am J Public Health. 2003;93(7):1041-4.

31. Berwick DM. Screening in health fairs. A critical review of benefits, risks, and costs. JAMA. 1985;254(11):1492-8.

32. Bryan JM, Deveraux JM, York ML, Schoh RJ. How effective are health fairs? Quantitative evaluation of a community health fair. Am J Health Promot. 1991;6(2):85-8.

33. Piette JD, Weinberger M, McPhee SJ. The effect of automated calls with telephone nurse follow-up on patient-centered outcomes of diabetes care: a randomized, controlled trial. Med Care. 2000;38(2):218-30.

34. Piette JD, Weinberger M, McPhee SJ, Mah CA, Kraemer FB, Crapo LM. Do automated calls with nurse follow-up improve self-care and glycemic control among vulnerable patients with diabetes? Am J Med 2000; 108(1):20-7

35. Piette JD, McPhee SJ, Weinberger M, Mah CA, Kraemer FB. Use of automated telephone disease management calls in an ethnically diverse sample of low-income patients with diabetes. Diabetes Care. 1999;22 (8): 1302-1309.

36. Sherwin R. Blood pressure in minorities screened for the Multiple Risk Factor Intervention Trial (MRFIT). Public Health Rep. 1996;111(Suppl 2):68-70.

37. Translating Research into Action For Diabetes Study Instruments. Available at: http://www.triadstudy.org/instruments_tools/study instruments.htm. Accessed February 3, 2010.

38. Michigan Diabetes Research and Training Center. Available at: http://www. med.umich.edu/mdrtc/profs/survey.html. Accessed February 3, 2010.

39. Smedley BD, Syme SL. Institute of Medicine. Committee on capitalizing on social science and behavioral research to improve the public's health. 
Promoting health: intervention strategies from social and behavioral research. Washington: National Academy Press; 2000.

40. Zuvekas A, Nolan L, Tumaylle C, Griffin L. Impact of community health workers on access, use of services, and patient knowledge and behavior. J Ambul Care Manage. 1999;22(4):33-44.

41. Cristancho S, Garces DM, Peters KE, Mueller BC. Listening to Rural Hispanic immigrants in the Midwest: a community-based participatory assessment of major barriers to health care access and use. Qual Health Res. 2008; 18(5):633-46.

42. Brown E, Ojeda V, Wyn R, Levan R. Racial and ethnic disparities in access to health insurance and health care. Los Angeles: UCLA Center for Health Policy Research and The Henry J. Kaiser Family Foundation; 2000.

43. Pippins JR, Alegria M, Haas JS. Association between language proficiency and the quality of primary care among a national sample of insured Latinos. Med Care. 2007;45(11):1020-1025.

44. Lauderdale D. Immigrant perceptions of discrimination in health care: the California Health Interview Survey 2003. Med Care. 2006;44(10):914-20.

45. Coldewey LJ. Parish nursing: a system approach. Suggestions for planning and implementing parish partnerships. Health Prog. 1993;74 (9):54-57, 66 .
46. Appel LJ, Champagne CM, Harsha DW, et al. Effects of comprehensive lifestyle modification on blood pressure control: main results of the PREMIER clinical trial. JAMA. 2003;289(16):2083-2093.

47. Carter-Edwards L, Jallah YB, Goldmon MV, Roberson JT Jr, Hoyo C. Key attributes of health ministries in African American churches: an exploratory survey. N C Med J. 2006;67(5):345-50.

48. Rydholm L, Kirkhorn SR. A study of the impact and efficacy of health fairs for farmers. J Agric Saf Health. 2005;11(4):441-8.

49. Viera AJ, Jamieson B. How effective are hypertension self-care interventions? J Fam Pract. 2007;56(3):229-31

50. Viera AJ, Kshirsagar AV, Hinderliter AL. Lifestyle modifications to lower or control high blood pressure: is advice associated with action? The behavioral risk factor surveillance survey. J Clin Hypertens (Greenwich). 2008;10(2):105-11.

51. United States Preventive Services Task Force Screening Guidelines. Available at: http://www.ahrq.gov/clinic/USpstfix.htm. Accessed February 3, 2010

52. Tonstad S, Alm CS, Sandvik E. Effect of nurse counselling on metabolic risk factors in patients with mild hypertension: a randomised controlled trial. Eur J Cardiovasc Nurs. 2007;6(2):160-4. 